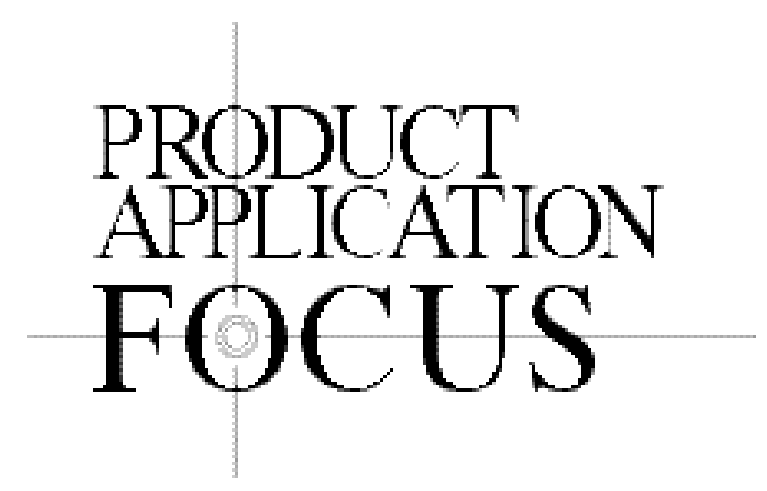

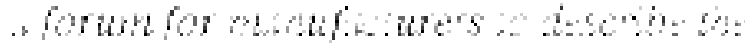

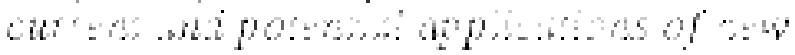

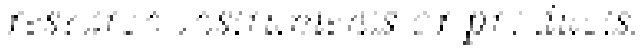

\title{
Detection of Caspase Activation In Situ by Fluorochrome-Labeled Caspase Inhibitors
}

\author{
P.A. Amstad, G. Yu, G.L. Johnson' ${ }^{1}$ B.W. Lee ${ }^{1}$, S. Dhawan ${ }^{2}$, and D.J. Phelps ${ }^{3}$ \\ Intergen Discovery Products, Gaithersburg, MD, Immunochemistry Technologies, \\ Bloomington, ${ }^{2}$ Cell Technology, Minneapolis, MN, and ${ }^{3}$ Intergen, Purchase, NY, USA
}

\begin{abstract}
Apoptosis is dependent on the activation of a group of proteolytic enzymes called caspases. Caspase activation can be detected by im munoblotting using caspase-specific antibodies or by caspase activity measurement employing pro-fluorescent substrates that become fluorescent upon cleavage by the caspase. Most of these methods require the preparation of cell extracts and, therefore, are not suitable for the detection of active caspases within the living cell. Using FAM-VAD-FMK, we have developed a simple and sensitive assay for the detection of caspase activity in living cells. FAM-VAD-FMK is a carboxyfluorescein (FAM) derivative of benzyloxycarbonyl-valinealanine-aspartic acid-fluoromethyl ketone (zVAD-FMK), which is a potent broad-spectrum inhibitor of caspases. FAM-VAD-FMK enters the cell and irreversibly binds to activated caspases. Cells containing bound FAM-VAD-FMK can be analyzed by flow cytometry, fluorescence microscopy, or a fluorescence plate reader. Using FAM$V A D-F M K$, we have measured caspase activation in live non-adherent and adherent cells. We show that FAM-VAD-FMK labeled Jurkat and HeLa cells that had undergone apoptosis following treatment with camptothecin or staurosporine. Non-stimulated negative control cells were not stained. Pretreatment with the general caspase inhibitor zVAD-FMK blocked caspase-specific staining in induced Jurkat and HeLa cells. Pretreatment of staurosporine-induced Jurkat cells with FAM-VAD-FMK inhibited affinity labeling of caspase-3, -6, and -7, blocked caspase-specific cell staining, and led to the inhibition of apoptosis. In contrast, the fluorescent control inhibitor FAM-FA-FMK had no effect. Measurement of caspase activation in 96-well plates showed a 3-to 5-fold increase in FAM-fluorescence in staurosporine-treated cells compared to control cells. In summary, we show that FAM-VAD-FMK is a versatile and specific tool for detecting activated caspases in living cells.
\end{abstract}

\section{INTRODUCTION}

Apoptosis is an evolutionarily conserved form of cell suicide that follows a specialized cellular process. The central component of this process is a cascade of proteolytic enzymes called caspases (14). These enzymes participate in a series of reactions that are triggered in response to pro-apoptotic signals and result in cleavage of protein substrates, causing the disassembly of the cell (20). The mammalian caspases play distinct roles in apoptosis and inflammation (12). In apoptosis, caspases are responsible for proteolytic cleavages that lead to cell disassembly (effector caspases) and are involved in upstream regulatory events (initiator caspases) (16). An active caspase consists of two large (about $20 \mathrm{kDa}$ ) and two small (about $10 \mathrm{kDa}$ ) subunits to form two heterodimers that associate in a tetramer. In common with other proteases, caspases are synthesized as precursors that undergo proteolytic maturation, either autocatalytically or in a cascade by enzymes with similar specificity $(13,16,18,19)$. Caspase enzymes selectively recognize a four amino acid sequence with an absolute requirement for aspartate at the $\mathrm{P}_{1}$ position.

Various approaches have been used to measure caspase activation. Among these techniques, immunoblotting and fluorogenic caspase substrates are the most widely used. Measuring caspase activation by immunoblotting is based on the detection of caspase cleavage products, which differ in molecular weight from the pro-caspases, using caspase-specific antibodies (21). Fluorogenic substrates consist of a peptide comprising the caspase recognition sequence linked to a fluorogenic reporter moiety. Upon cleavage of the fluorogenic substrate at the junction of the aspartic acid and the fluorogenic reporter molecule, the fluorescence of the reporter 
becomes activated and can be detected by fluorescence spectroscopy (fluorescence plate reader). The most widely used fluorogenic caspase substrates, which are based on 7-amido4-methylcoumarin (AMC) (7) or 7-amido-4-(trifluoromethyl)coumarin (AFC), can only be used to measure caspase activation in cell extracts and not in live cells because coumarin-labeled peptide substrates are cell impermeable and they excite at 380 and $400 \mathrm{~nm}$, respectively, where autofluorescence of cells interferes with the measurement (11). Recently, new fluorogenic caspase substrates have been developed. One of these substrates is a derivative of rhodamine 110 containing the caspase-3 substrate recognition sequence DEVD covalently linked to rhodamine 110 (10). Upon enzymatic cleavage, the non-fluorescent substrate is converted into the fluorescent rhodamine 110. Although this substrate can be used to measure caspase- 3 activity in a homogeneous assay either with cells or with cell extracts, it is not suitable for caspase detection in individual cells in situ because fluorescent rhodamine 110 diffuses out of the cell, leading to loss of staining. A new class of fluorogenic caspase substrates has been developed by OncoImmunin, Gaithersburg, MD, USA (9). These substrates are cell permeable and become fluorescent upon cleavage by the caspase inside the cell.

We have developed a novel approach to detect active caspases in living cells. The methodology is based on carboxyfluorescein (FAM)-labeled fluoromethyl ketone (FMK)-peptide inhibitors of caspases $(4,6)$. These inhibitors are cell permeable and non-cytotoxic. Once inside the cell, the inhibitor binds irreversibly to the active centers of the caspases ensuring that only cells with activated caspases become labeled. Because of irreversible binding of FAM-VAD-FMK to caspases, caspase activation in each individual cell can be detected. In contrast, the fluorescent moieties of fluorogenic substrates diffuse out of the cell, limiting the sensitivity of caspase detection in single cells. Here, we show that FAMVAD-FMK fluorescently labeled apoptotic Jurkat or HeLa cells but did not label control cells. Using FAM-VAD-FMK, caspase activation in living cells was measured by flow
A: Control

B: Camptothecin

C: Camptothecin + zVAD-FMK
Jurkat
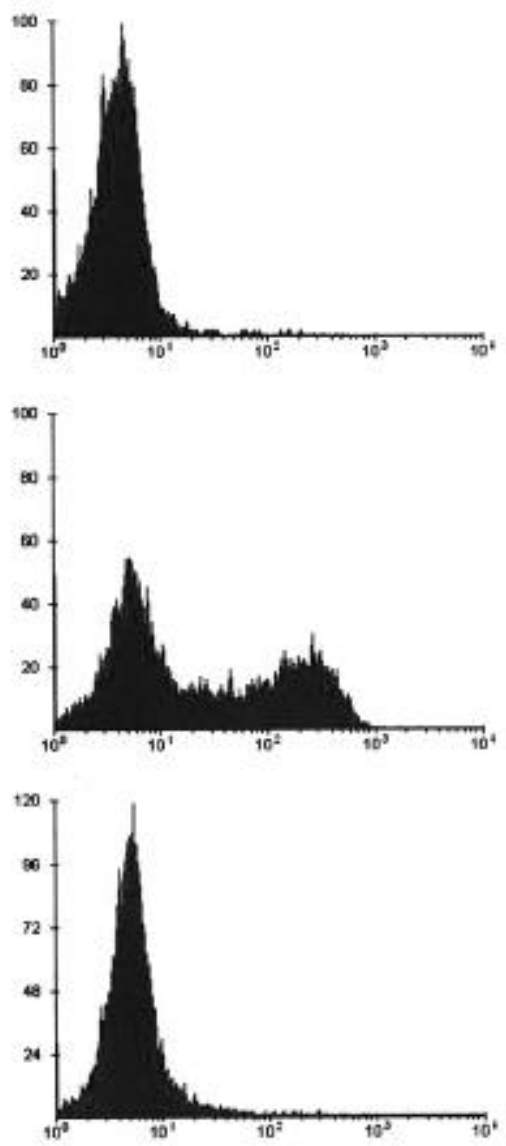

HeLa
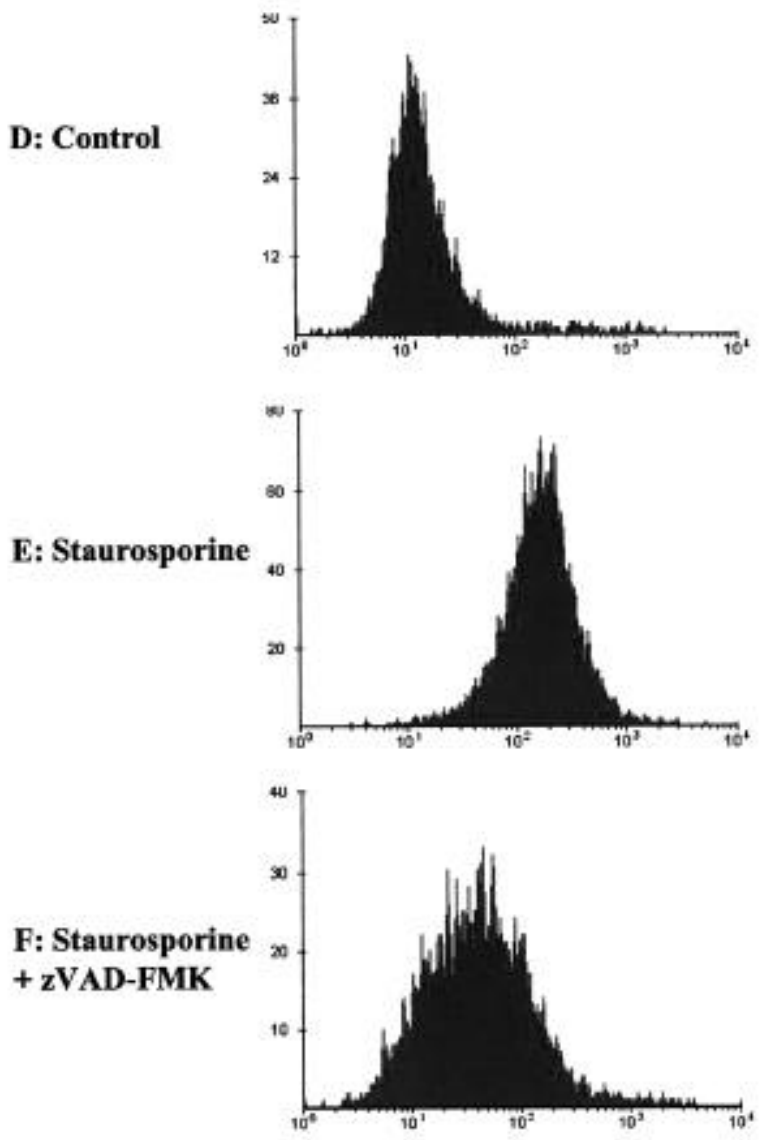

Figure 1. In situ caspase detection by flow cytometry. Jurkat cells were DMSO treated (A) or treated with $2 \mu \mathrm{g} / \mathrm{mL}$ camptothecin with (C) and without (B) 50 $\mu \mathrm{M} \mathrm{zVAD}-F M K$ for $4 \mathrm{~h}$. Cells were labeled with FAM-VAD-FMK for $1 \mathrm{~h}$, followed by washing and analysis by flow cytometry. HeLa cells were treated with DMSO (D) or $1 \mu \mathrm{M}$ staurosporine with (F) and without (E) $50 \mu \mathrm{M}$ zVAD-FMK for $4 \mathrm{~h}$. Cells were harvested by trypsinization, labeled with FAM-VAD-FMK for $1 \mathrm{~h}$, washed, and analyzed on a Coulter Epics flow cytometer. The flow cytometry frequency histograms of the number of events (Y-axis) versus the FAM fluorescence intensity (X-axis) show two peaks. Caspase-negative cells occur within the first log decade of the $\mathrm{X}$-axis, whereas caspase-positive cells lay within the second and third log decade. 
cytometry, fluorescence microscopy, or a fluorescence plate reader. Fluorescence labeling of apoptotic cells was dependent on binding of FAM-VAD-FMK to activated caspases inside the cell.

\section{MATERIALS AND METHODS}

\section{Cells}

The human $\mathrm{T}$ cell leukemia cell line Jurkat was obtained from ATCC (Manassas, VA, USA). Cells were maintained in RPMI 1640 supplemented with $10 \%$ fetal calf serum (FCS) and $2 \mathrm{mM}$ L-glutamine. Cultures with fewer than $5 \times 10^{5}$ cells $/ \mathrm{mL}$ were used for experiments. The human adenocarcinoma cell line, HeLa, was obtained from ATCC, and cells were cultured in EMEM medium supplemented with $10 \%$ FCS and $2 \mathrm{mM}$ L-glutamine. All cells were maintained in 5\% $\mathrm{CO}_{2}$ at $37^{\circ} \mathrm{C}$.

\section{Induction of Apoptosis}

Exponentially growing Jurkat cells adjusted to $10^{6}$ cells/mL were stimulated with either $2 \mu \mathrm{g} / \mathrm{mL}$ topoisomerase I inhibitor camptothecin (Sigma, St. Louis, MO, USA) for 4 $\mathrm{h}$ or $1 \mu \mathrm{M}$ concentrations of the protein kinase inhibitor, staurosporine (STS) (Sigma) for $4 \mathrm{~h}$. HeLa cells were plated onto $35-\mathrm{mm}$ petri dishes at $2 \times 10^{5}$ cells/dish and grown for $16 \mathrm{~h}$. The following day, cells were treated with $1 \mu \mathrm{M}$ staurosporine for $4 \mathrm{~h}$. Where indicated, cells were simultaneously co-exposed to $50 \mu \mathrm{M}$ caspase inhibitor zVAD-FMK (Enzyme Systems Products, Livermore, CA, USA).

\section{Caspase Detection by FAM-VAD-FMK}

FAM-VAD-FMK is commercially available as a component of the CaspaTag ${ }^{\mathrm{TM}}$ Fluorescein Caspase Activity Kit (Intergen Discovery Products, Gaithersburg, MD, USA). As specified in the kit, the FAM-VAD-FMK inhibitor was dissolved in dimethyl sulfoxide (DMSO) to obtain a $150 \times$ stock solution. Aliquots of this solution were stored at $-20^{\circ} \mathrm{C}$ in the dark. Before use, a 30× working solution of FAM-VAD-FMK was prepared by diluting the stock solution 1:5 in PBS. For labeling, a $300-\mu \mathrm{L}$ aliquot of cells was transferred to a fresh tube. Ten microliters of $30 \times$ FAM-VAD-FMK were added directly to the cell suspension. The cells were gently mixed and incubated for $1 \mathrm{~h}$ at $37^{\circ} \mathrm{C}$ under $5 \% \mathrm{CO}_{2}$ with tubes protected from light. Cells were washed twice with $1 \times$ Wash Buffer (PBS containing $0.5 \%$ bovine serum albumin and $0.05 \%$ sodium azide). Finally, the cell pellet was resuspended in $400 \mu \mathrm{L} 1 \times$ Wash Buffer. Cells were kept on ice and were analyzed by flow cytometry within $1 \mathrm{~h}$. Flow cytometry analysis was done on an EPICS $^{\mathrm{TM}}$ flow cytometer (Beckman Coulter, Fullerton, CA, USA) using a $15-\mathrm{mW}$ argon ion laser at $488 \mathrm{~nm}$. FAM fluorescence was measured with a $530 \pm 30 \mathrm{~nm}$ bandpass filter.

For measuring apoptosis, Jurkat cells were treated with 1 $\mu \mathrm{M}$ staurosporine for $3 \mathrm{~h}$ in the presence and absence of 10 , 50 , or $100 \mu \mathrm{M}$ FAM-VAD-FMK. The nuclei were stained with $1 \mu \mathrm{g} / \mathrm{mL}$ Hoechst 33342 (Sigma) for $5 \mathrm{~min}$, followed by washing and resuspension of cells in Wash Buffer. To quantify apoptosis, the percentage of cells with changes in nuclear morphology (nuclei with condensed chromatin and apoptotic bodies) was determined.
To measure caspase staining in HeLa cells, the supernatants of treated and control cells, grown in 35-mm dishes, were collected and transferred to sterile centrifuge tubes. The remaining attached cells were trypsinized and combined with the supernatants. Cells were centrifuged at $400 \times g$, washed twice with complete medium, and resuspended in $300 \mu \mathrm{L}$ complete medium. For labeling, $10 \mu \mathrm{L} 30 \times$ FAM-VAD-FMK was added and incubated for $1 \mathrm{~h}$ at $37^{\circ} \mathrm{C}$ under $5 \% \mathrm{CO}_{2}$. Cells were washed twice with $1 \times$ Wash Buffer, and the cell pellet was resuspended in $400 \mu \mathrm{L} 1 \times$ Wash Buffer, followed by flow cytometry analysis, as described above.

\section{Affinity Labeling of Caspases}

Jurkat cells $(200 \mu \mathrm{L})$ at $2 \times 10^{6}$ cells $/ \mathrm{mL}$ were treated with $1 \mu \mathrm{M}$ staurosporine in the presence or absence of the caspase inhibitors zVAD-FMK and FAM-VAD-FMK or the control peptide FAM-FA-FMK for $4 \mathrm{~h}$ at $37^{\circ} \mathrm{C}$ and $5 \% \mathrm{CO}_{2}$. Cells were affinity labeled with $10 \mu \mathrm{M}$ affinity label Ac-Tyr-ValLys(biotinyl)-Asp-2,6-dimethylbenzoyloxymethylketone (AcYVK(bio)D-aomk; Calbiochem) $(8,17)$ for an additional hour at $37^{\circ} \mathrm{C}$ and $5 \% \mathrm{CO}_{2}$. Affinity labeled cells were collected by centrifugation at $400 \times g$, washed once in ice-cold PBS, and lysed on ice for $10 \mathrm{~min}$ in Nonidet ${ }^{\circledR} \mathrm{P}-40$ buffer $(1 \%$ Nonidet P-40, 150 mM NaCl, 50 mM Tris-HCl, pH 7.4, containing $0.5 \mathrm{mM}$ phenylmethylsulfonyl fluoride, $5 \mu \mathrm{g} / \mathrm{mL}$ aprotinin, $5 \mu \mathrm{g} / \mathrm{mL}$ pepstatin, and $5 \mu \mathrm{g} / \mathrm{mL}$ leupeptin). Sam ples were vortex mixed and centrifuged for $5 \mathrm{~min}$ at $19000 \times \mathrm{g}$ at $4^{\circ} \mathrm{C}$. An equal volume of $2 \times$ gel loading buffer was added to $15 \mu \mathrm{L}$ cleared extract. The samples were heated at $95^{\circ} \mathrm{C}$ for $5 \mathrm{~min}$. Proteins were resolved on a $15 \%$ SDS-polyacrylamide gel and transferred to nitrocellulose membranes. Nonspecific binding was blocked with TBS-T (50 mM Tris- $\mathrm{HCl}, \mathrm{pH} 7.5$,

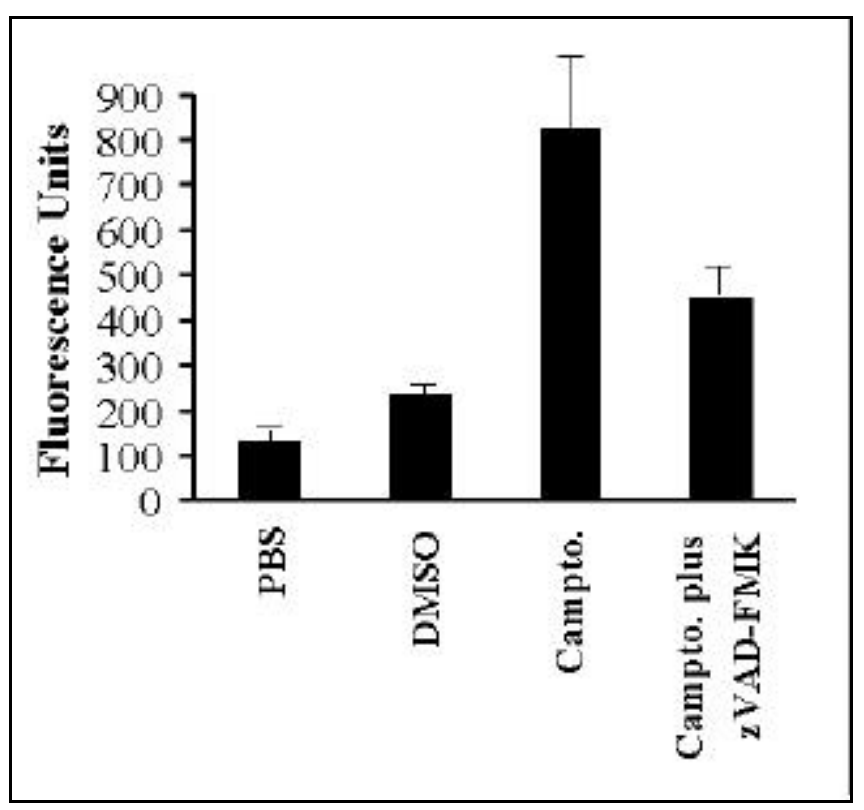

Figure 2. Inhibition of caspase staining by co-treatment with zVADFMK. Jurkat cells were DMSO treated and treated with $2 \mu \mathrm{g} / \mathrm{mL}$ camptothecin for $6 \mathrm{~h}$. Then, cells were labeled with $10 \mu \mathrm{M}$ FAM-VAD-FMK in the presence and absence of $50 \mu \mathrm{M} \mathrm{zVAD}$-FMK for $1 \mathrm{~h}$. Cells were washed three times with wash buffer and resuspended in $300 \mu \mathrm{L}$ PBS. Aliquots $(100 \mu \mathrm{L})$ were transferred to wells of a black 96-well plate. FAM-fluorescence was read in a Victor 1420 fluorescence plate reader at $485 \mathrm{~nm}$ excitation and 535 $\mathrm{nm}$ emission wavelengths. Error bars, SD of three wells. 
$150 \mathrm{mM} \mathrm{NaCl}, 0.1 \%$ Tween ${ }^{\circledR} 20$ ) containing 5\% non-fat dry milk for $1 \mathrm{~h}$ at room temperature. After washing two times with TBS-T, the membranes were probed with horseradish peroxidase-linked streptavidin (1:2000 dilution in TBS-T with $1 \%$ bovine serum albumin) for $1 \mathrm{~h}$. The blots were washed four times with TBS-T. Labeled proteins were visualized by enhanced chemiluminescence $\left(\mathrm{ECL}^{\circledR}\right)$ according to the manufacturer's instructions (SuperSignal ${ }^{\circledR}$; Pierce Chemical, Rockford, IL, USA).

\section{Caspase Detection in Non-Adherent and Adherent Cells Using 96-Well Plates}

Non-adherent Jurkat cells $(150 \mu \mathrm{L})$ at $2 \times 10^{6}$ cells $/ \mathrm{mL}$ were plated per well of a black 96-well plate (Cliniplate ${ }^{\mathrm{TM}}$; Labsystems, Franklin, MA, USA). Cells were treated with solvent control (DMSO) or with $1 \mu \mathrm{M}$ staurosporine with and without $50 \mu \mathrm{M} \mathrm{zVAD}-\mathrm{FMK}$ for $4 \mathrm{~h}$ at $37^{\circ} \mathrm{C} / 5 \% \mathrm{CO}_{2}$. To label, $5 \mu \mathrm{L} 30 \times$ FAM-VAD-FMK were added per well, and incubation was continued for $1 \mathrm{~h}$ at $37^{\circ} \mathrm{C} / 5 \% \mathrm{CO}$. The 96-well plate was centrifuged for $5 \mathrm{~min}$ at $600 \times \mathrm{g}$ at room temperature, and the supernatant was removed by vacuum aspiration. The wells were washed three times with $300 \mu \mathrm{L} 1 \times$ Wash Buffer followed by centrifugation at $600 \times g$ after each wash. PBS $(100 \mu \mathrm{L})$ was added per well, and fluorescence was read in a Victor 1420 fluorescence plate reader (Applied Biosystems, Foster City, CA, USA) at $485 \mathrm{~nm}$ excitation and $535 \mathrm{~nm}$ emission wavelengths.

HeLa cells were trypsinized and seeded onto wells of a black 96-well plate with clear bottom (Applied Biosystems) at a cell density of $5 \times 10^{4}$ cells/well and grown to confluence for $16 \mathrm{~h}$ at $37^{\circ} \mathrm{C} / 5 \% \mathrm{CO}_{2}$. In a total volume of $100 \mu \mathrm{L}$, cells were treated with solvent control (DMSO) or $1 \mu \mathrm{M}$ staurosporine with and without $50 \mu \mathrm{M} \mathrm{zVAD}-\mathrm{FMK}$ for $4 \mathrm{~h}$ at $37^{\circ} \mathrm{C} / 5 \% \mathrm{CQ}$. Labeling of cells was performed by the addition of $3.3 \mu \mathrm{L} 30 \times$ FAM-VAD-FMK per well, and incubation was continued at $37^{\circ} \mathrm{C} / 5 \% \mathrm{CO}_{2}$ for $1 \mathrm{~h}$. Two-hundred microliters of $1 \times$ Wash Buffer were added, followed by centrifugation at $600 \times g$ for 5 min at room temperature. The supernatant was removed by vacuum aspiration. The wells were washed twice with $300 \mu \mathrm{L}$ $1 \times$ Wash Buffer, followed by centrifugation after each wash. PBS $(100 \mu \mathrm{L})$ was added per well, and fluorescence was read in a Victor 1420 fluorescence plate reader at $485 \mathrm{~nm}$ excitation and $535 \mathrm{~nm}$ emission wavelengths.

\section{RESULTS AND DISCUSSION}

\section{In Situ Caspase Detection by FAM-VAD-FMK}

We have developed the fluorescein-labeled general caspase inhibitor FAM-VAD-FMK as a reagent to detect active caspases in living cells using flow cytometry, fluorescence microscopy, or a fluorescence plate reader. The flow cytometry histogram in Figure 1A shows one peak within the first log decade of the $\mathrm{X}$-axis corresponding to unstained control cells. The histogram of camptothecin-induced Jurkat cells displays two peaks (Figure 1B). The peak within the first log decade corresponds to unstained non-apoptotic cells, whereas the peak appearing within the second and third log decade corresponds to FAM-VAD-FMK-stained apoptotic cells. The increase in caspase-specific fluorescence in apoptotic cells compared to non-apoptotic cells was 30 -fold. The fluorescence intensity of labeled non-apoptotic cells was approximately twice that of the autofluorescence generated by unstained cells (data not shown), indicating low background staining of non-apoptotic cells by FAM-VAD-FMK. Pretreatment with the pan-caspase inhibitor zVAD-FMK (Figure 1C) completely blocked caspase-specific fluorescence cell staining, indicating that FAM-VAD-FMK specifically labels cells containing active caspases.

To extend our findings with non-adherent Jurkat cells to other cell types, we examined caspase-specific cell staining in apoptotic and control HeLa cells. The flow cytometry histogram of staurosporine-treated HeLa cells (Figure 1E) shows a single peak within the second log decade of the $\mathrm{X}$-axis with a median fluorescence 10-fold higher than with control cells, which show a peak within the first log decade of the X-axis (Figure 1D). Similar to Jurkat cells, pretreatment with zVADFMK (Figure 1F) blocked caspase-specific fluorescence cell staining in staurosporine-treated HeLa cells.

We have proposed that the observed labeling of apoptotic cells with FAM-VAD-FMK is due to the specific binding of FAM-VAD-FMK to caspases, which thereby inhibits the enzyme, and is not a reflection of nonspecific binding to intracellular targets as a consequence of an apoptosis-related increase in cell permeability, nor is it due to cleavage of non-caspase cellular proteins by caspase enzymes (1). To prove this claim, we measured caspase labeling in Jurkat cells treated with camptothecin for $6 \mathrm{~h}$, followed by incubation with FAM-VAD-FMK with and without $\mathrm{zVAD}$-FMK for $1 \mathrm{~h}$. As shown in Figure 2, co-treatment with zVAD-FMK blocked staining with FAM-VAD-FMK, indicating that both $\mathrm{zVAD}$ FMK and FAM-VAD-FMK compete for the same intracellular target, namely activated caspases.

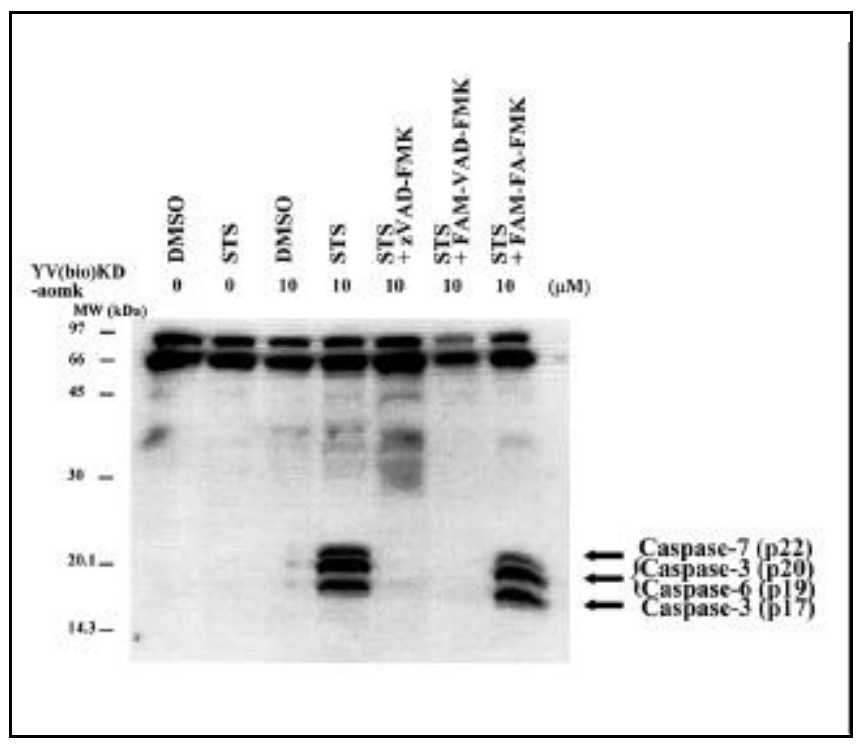

Figure 3. Caspase detection by affinity labeling. Jurkat cells were treated with $1 \mu \mathrm{M}$ staurosporine (STS) in the presence or absence of the caspase inhibitor zVAD-FMK, FAM-VAD-FMK, or the control peptide FAM-FA-FMK for $4 \mathrm{~h}$. A $10 \mu \mathrm{M}$ concentration of the affinity label AcYVK(bio)D-aomk was added, and incubation was continued for $1 \mathrm{~h}$. As controls, DMSO- and staurosporine-treated cells were incubated for $1 \mathrm{~h}$ without affinity label. Cells were washed, and cell lysates were prepared. Proteins were separated on a SDS-polyacrylamide gel, followed by transfer to nitrocellulose membranes. Labeled proteins were revealed by streptavidin-horseradish peroxidase com bined with ECL detection. 
Since zVAD-FMK has been shown to prevent apoptosis by inhibiting caspases (2), it is reasonable to propose that FAM-VAD-FMK would also irreversibly bind to and inhibit active caspases, thus preventing induction of apoptosis. To examine this, we measured apoptosis in staurosporine-treated cells with and without FAM-VAD-FMK. Apoptosis was quantified by counting cells with apoptotic nuclear morphology using Hoechst stain. As shown in Table 1, co-treatment of staurosporine-stimulated cells with FAM-VAD-FMK led to a decrease in the percentage of apoptotic cells. These results demonstrate that FAM-VAD-FMK acts as an inhibitor of apoptosis by inhibiting the caspase cascade. We have previously shown that there exists a strong correlation between the apoptotic index as estimated by DNA strand break labeling (TUNEL assay) and the activation of caspases in cells treated with camptothecin (1). This clearly indicates that caspase activation can be used as a definite and reliable indicator for apoptosis.

\section{FAM-VAD-FMK Inhibits Effector Caspases}

Figures 1 and 2 show that cell staining with FAM-VADFMK is inhibited by the general caspase inhibitor zVADFMK. This suggests that FAM-VAD-FMK binds to and inhibits activated caspases. To examine the specificity of FAM-VAD-FMK and zVAD-FMK for inhibiting caspases, caspase activation was measured in staurosporine-treated cells in the presence and absence of FAM-VAD-FMK or zVADFMK by affinity labeling. As shown in Figure 3, the pattern of affinity-labeled bands is identical to that published by Takahashi et al. (15), who found that the four bands corresponded to caspase- 3 fragments p17 and p20, to caspase- 6 fragment $\mathrm{p} 19$, and to caspase-7 fragment $\mathrm{p} 22$. Fragments $\mathrm{p} 19$ and $\mathrm{p} 20$ appear as one band on a $15 \%$ SDS-polyacrylamide gel. We confirmed the published band identification (15) using specific inhibitors for caspase-3, caspase- 3 and -7, and caspase-6 (data not shown). The affinity label AcYVK(bio)D-aomk only detects effector caspases, but not initiator caspases, because the latter are much less abundant (5). Staurosporine treatment of Jurkat cells led to activation of caspase-3, -6, and -7. DMSO-treated affinity labeled cells did not show any bands corresponding to activated caspases, nor did unlabeled DMSO-treated or unlabeled staurosporine-treated cells. Both zVAD-FMK and FAM-VAD-FMK inhibited affinity labeling of all the caspase fragments. As a control, the FAM-labeled cathepsin B inhibitor FAM-FA-FMK (3) did not inhibit caspase labeling. These results show that FAM-VAD-FMK and zVAD-FMK inhibit caspase labeling because of the inhibition of caspase activation, resulting in inhibition of apoptosis.

\section{Caspase Detection in Microplates}

Human disease pathogenesis often reveals an apoptotic component that either contributes to disease progression or is the direct cause. To discover drugs specific for apoptosis-related diseases, new screening technologies using living cells are required. Because of their pivotal role in cell death, caspases are the most obvious therapeutic targets for modulating
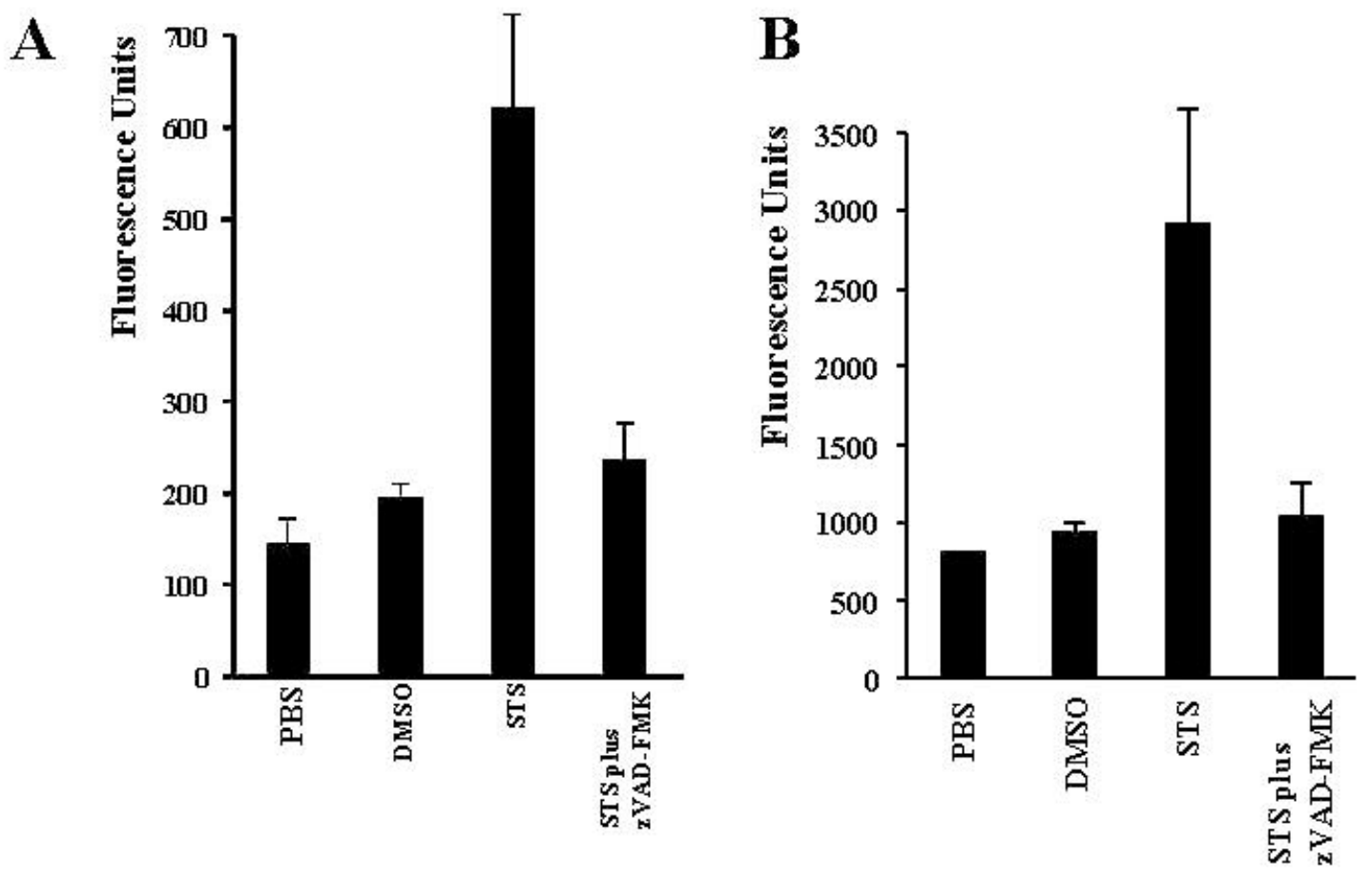

Figure 4. Caspase detection in 96-well plates. Jurkat cells (A) or HeLa cells (B) were plated into wells of a black 96-well plate. Cells were control treated (DMSO), treated with $1 \mu \mathrm{M}$ staurosporine (STS), or co-treated with $1 \mu \mathrm{M}$ staurosporine plus $50 \mu \mathrm{M}$ zVAD-FMK for $4 \mathrm{~h}$. After labeling with FAM-VAD-FMK, cells were washed and FAM-fluorescence was read in a Victor 1420 fluorescence plate reader at $485 \mathrm{~nm}$ excitation and $535 \mathrm{~nm}$ emission wavelengths. Error bars, SD of two wells. 
Table 1. Inhibition of Apoptosis by FAM-VAD-FMK

\begin{tabular}{|c|c|}
\hline & $\%$ Apoptosis \\
\hline DMSO & 2.5 \\
\hline STS & 74 \\
\hline STS plus & 56 \\
\hline \multicolumn{2}{|c|}{$10 \mu \mathrm{M}$ FAM-VAD-FMK } \\
\hline STS plus & 12 \\
\hline \multicolumn{2}{|c|}{$50 \mu \mathrm{M}$ FAM-VAD-FMK } \\
\hline STS plus & 13 \\
\hline \multicolumn{2}{|c|}{$100 \mu \mathrm{M}$ FAM-VAD-FMK } \\
\hline \multicolumn{2}{|c|}{$\begin{array}{l}\text { Jurkat cells were control treated, treated with } 1 \mu \mathrm{M} \\
\text { staurosporine (STS), or co-treated with } 1 \mu \mathrm{M} \text { STS plus } \\
\text { increasing concentrations of FAM-VAD-FMK for } 3 \mathrm{~h} \text {. Cells } \\
\text { were subsequently stained with Hoechst to detect } \\
\text { apoptotic nuclei. After washing, an aliquot of cells was } \\
\text { placed on a microscope slide, and nuclear staining was } \\
\text { observed using a UV filter (excitation } 395 \mathrm{~nm} \text {, emission } \\
450 \mathrm{~nm} \text { ). The percentage of apoptosis was determined } \\
\text { from apoptotic nuclei cell counts of at least } 100 \text { cells. }\end{array}$} \\
\hline
\end{tabular}

apoptosis. To determine whether FAM-VAD-FMK could be used in an apoptotic drug screen, we measured caspase activation in staurosporine-treated Jurkat cells or HeLa cells by fluorescence spectroscopy using 96-well plates. As shown in Figure 4A, staurosporine treatment of Jurkat cells led to a 3fold increase in FAM-fluorescence compared to control cells. FAM-fluorescence in staurosporine-treated HeLa cells was also increased 3-fold compared to control cells (Figure 4B). Pretreatment with zVAD-FMK completely abolished the staurosporine induced increase in fluorescence in Jurkat and HeLa cells. These results show that FAM-VAD-FMK can be used to measure caspase activation in living cells following drug treatment using a 96-well plate format.

In conclusion, FAM-VAD-FMK is a sensitive and specific reagent for the detection of activated caspases in living cells.

\section{REFERENCES}

1.Bedner, E., P. Smolewski, P.A. Amstad, and Z. Darzynkiewicz. 2000. Activation of caspases measured in situ by binding or fluorochrome-labeled inhibitors of caspases (FLICA): correlation with DNA fragmentation. Exp. Cell Res. 259:308-313.

2.Bossy-Wetzel, E., D.D. Newmeyer, and D.R. Green. 1998. Mitochondrial cytochrome $\mathrm{c}$ release in apoptosis occurs upstream of DEVD-specific caspase activation and independent of mitochondrial transmembrane depolarization. EMBO J. 17:37-49.

3.Eichhold, T.H., E.B. Hookfin, Y.O. Taiwo, B. De, and K.R. Wehmeyer. 1997. Isolation and quantification of fluoroacetate in rat tissues, following dosing of Z-Phe-Ala-CH2-F, a peptidyl fluoromethyl ketone protease inhibitor. J. Pharm. Biomed. Anal. 16:459-467.

4.Ekert, P G., J. Silke, and D.L. Vaux. 1999. Caspase inhibitors. Cell Death Differ. 6:1081-1086.

5.Faleiro, L., R. Kobayashi, H. Fearnhead, and Y. Lazebnik. 1997. Multiple species of CPP32 and Mch2 are the major active caspases present in apoptotic cells. EMBO J. 16:2271-2281.

6.Garcia-Calvo, M., E. Peterson, B. Leiting, R. Ruel, D. Nicholson, and N. Thornberry. 1998. Inhibition of human caspases by peptide-based and macromolecular inhibitors. J. Biol. Chem. 273:32608-32613.

7.Gurtu, V., S.R. Kain, and G. Zhang. 1997. Fluorometric and colorimetric detection of caspase activity associated with apoptosis. Anal. Biochem. 251:98-102.

8.Hirata, H., A. Takahashi, S. Kobayashi, S. Yonehara, H. Sawai, T. Okazaki, K. Yamamoto, and M. Sasada. 1998. Caspases are activated in a branched protease cascade and control distinct downstream processes in Fas-induced apoptosis. J. Exp. Med. 187:587-600.

9.Komoriya, A., B.Z. Packard, M.J. Brown, M.L. Wu, and P.A. Henkart. 2000. Assessment of caspase activities in intact apoptotic thymocytes using cell-permeable fluorogenic caspase substrates. J. Exp. Med. 191:1819-1828.

10.Liu, J., M. Bhalgat, C. Zhang, Z. Diwu, B. Hoyland, and D.H. Klaubert. 1999. Fluorescent molecular probes V: a sensitive caspase-3 substrate for fluorometric assays. Bioorg. Med. Chem. Lett. 9:3231-3236

11.Mizukami, S., K. Kikuchi, T. Higuchi, Y. Urano, T. Mashima, T. Tsuruo, and T. Nagano. 1999. Imaging of caspase-3 activation in HeLa cells stimulated with etoposide using a novel fluorescent probe. FEBS Lett. 453:356-360.

12.Nicholson, D.W. and N.A. Thornberry. 1997. Caspases: killer proteases. Trends Biochem. Sci. 22:299-306.

13.Rotonda, J., D.W. Nicholson, K.M. Fazil, M. Gallant, Y. Gareau, M. Labelle, E.P. Peterson, D.M. Rasper et al. 1996. The three-dimensional structure of apopain/CPP32, a key mediator of apoptosis. Nat. Struct. Biol. 3:619-625.

14.Slee, E.A., C. Adrain, and S.J. Maritin. 1999. Serial killers: ordering caspase activation events in apoptosis. Cell Death Differ. 6:1067-1074.

15.Takahashi, A., H. Hirata, S. Yonehara, Y. Imai, K. Lee, R. Moyer, P. Turner, P. Mesner et al. 1997. Affinity labeling displays the stepwise activation of ICE-related proteases by Fas, staurosporine, and CrmA-sensitive caspase-8. Oncogene 14:2741-2752.

16. Thornberry, N.A. and Y. Lazebnik. 1998. Caspases: enemies within. Science 281:1312-1316.

17.Thornberry, N.B., E.P. Peterson, J.J. Zhao, A.D. Howard, P.R. Griffin, and K.T. Chapman. 1994. Inactivation of interleukin-1 $\beta$ converting enzyme by peptide (acyloxy)methyl ketones. Biochemistry 33:39343940.

18.Walker, N.P., R.V. Talanian, K.D. Brady, L.C. Dang, N.J. Bump, C.R. Ferenz, S. Franklin, T. Ghayur et al. 1994. Crystal structure of the cysteine protease interleukin-1 $\beta$-converting enzyme: a (p20/p10) 2 homodimer. Cell 78:343-352.

19.Wilson, K.P., J.F. Black, J.A. Thomson, E.E. Kim, J.P. Griffith, M.A. Navia, M.A. Murcko et al. 1994. Structure and mechanism of interleukin-1 beta converting enzyme. Nature 370:270-275.

20.Wolf, B.B. and D.R. Green. 1999. Suicidal tendencies: apoptotic cell death by caspase family proteinases. J. Biol. Chem. 274:20049-20052.

21.Zhivotovsky, B., A. Samali, A.Gahm, and S. Orrenius. 1999. Caspases: their intracellular localization and translocation during apoptosis. Cell Death Differ. 8:644-651.

Address correspondence to Dr. Paul Amstad, Intergen Discovery Products, 202 Perry Parkway, Gaithersburg, MD 20877,USA.e-mail: p.amstad@intergenco.com
For reprints of this or any other article, contact Reprints@BioTechniques.com 